\title{
UMA INTRODUÇÃO AO RETORNO DA LEGITIMIDADE DE CONFÚCIO NA REPÚBLICA POPULAR DA CHINA ${ }^{1}$
}

\author{
Daniel Tiago de Vasconcelos ${ }^{2}$
}

\begin{abstract}
Resumo: Autores ocidentais chamam atenção para uma grande diversidade de formas de ativismo, expressões religiosas, práticas pedagógicas alternativas e, mesmo a ação do Estado em defesa de concepções tradicionais associadas ao confucianismo, principalmente após a morte de Mao Zedong em 1976. Este trabalho tenta articular o atual fenômeno conhecido como 'confucian revival', com alguns marcos e processos históricos anteriores, demonstrando as variações de defesa e crítica do confucianismo bem como da aceitação ou não, pelos chineses da imposição de ideias e estruturas sociais estrangeiras.
\end{abstract}

Palavras-chave: Novo Confucianismo; Sinização e Ocidentalização; Ativismo Neoconfuciano.

\begin{abstract}
Western scholars call attention to a wide variety of activisms, religious expressions, alternative pedagogical practices, and even state actions in defense of traditional conceptions associated with confucianism, especially after Mao Zedong's death in 1976. This paper attempts to articulate the current phenomenon known as 'confucian revival', with some milestones and previous historical processes, demonstrating the variations of defense and criticism of confucianism, as well the acceptance or nonacceptance of the imposition of foreign social ideas and structures by the Chinese.
\end{abstract}

Keywords: New Confucianism; Sinization and Westernization; Neoconfucian Activism.

\section{Introdução}

Pouco valorizado pelos ocidentais desde o século XIX, ${ }^{3}$ para os chineses, Confúcio (551-479 a. E. C.) adquiriu, ao longo dos séculos, o caráter tanto de intelectual incontestável quanto de santo sábio exemplo de retidão moral a ser seguida por toda humanidade. Mas, após o período denominado pelos chineses como 'Século da

${ }^{1}$ Este trabalho foi realizado no Grupo de Estudos Sobre História da Ásia, vinculado ao Departamento de História da UFPE. O presente artigo retoma temáticas desenvolvidas no Trabalho de Conclusão de Curso (TCC) de licenciatura em história.

${ }^{2}$ Licenciando em História na Universidade Federal de Pernambuco. Contato: R. Severino Lima da Silva, Santo Antônio, Bezerros - PE, Brasil. E-mail: danieltiagov@ hotmail.com.

${ }_{3}$ De fato, as concepções de meritocracia, concurso público, moral civil, ética dos governantes tornaram-se populares na Europa, tendo influenciado fortemente pensadores como Leibniz e Voltaire. Os jesuítas, que tinham contato com o confucianismo na China contribuíram muito para a tradução e divulgação dos textos confucianos. Contudo, no século XIX, ao mesmo tempo em que autores como Hegel apresentavam uma imagem da China negativa comparada à Europa, a dominação colonial e as Guerras do Ópio contribuíram para desvalorizar o pensamento político-filosófico chinês, associado ao quadro de miséria e atraso que o país sofria. Para maiores detalhes sobre a circulação dos textos confucianos no ocidente ver: REDYSON, Deyve. "Filosofia e Religião no Pensamento de Confúcio". GNERRE, Maria Lucia Abaurre. China Antiga: aproximações religiosas. São Paulo: Fonte Editorial, 2015, pp. 11-39. 
Humilhação'(1839-1949), a popularidade da tradição intelectual que se legitimava em nome do mesmo, a Escola Confuciana Rujia 儒家, foi drasticamente reduzida. Os ânimos da Grande Revolução Cultural Proletária (1966-1976) pareciam significar, além do fim do confucianismo na China continental, a vitória de um arcabouço teórico de origem estrangeira, o marxismo-leninismo. Mas, a sinologia e outros pesquisadores mais atentos percebiam que o maoísmo parecia conter vários elementos de um marxismo sinizado, e assim, houve uma tendência a relativizar até que ponto ocorreu uma ocidentalização da China por meio da implantação do socialismo. As questões sobre uma ocidentalização ou não foram colocadas, mais uma vez, frente ao contexto recente de globalização na qual a China está inserida. Por um lado, os ocidentais foram surpreendidos com um gigante asiático de difícil entendimento para seus critérios conceituais. Por outro, alguns vão defender que esse gigante parece assumir sua antiga posição de Império do Centro, e explicar, usando elementos da história e cultura tradicional chinesa, que não é uma surpresa a influência atual conquistada pela República Popular da China.

O presente artigo tenta evidenciar alguns marcos e pontos de disputas conceituais que evidenciam as mudanças da posição oficial dos governantes chineses, e de atores individuais, frente ao confucianismo. O termo 'confucianismo' é uma palavra que não existe em chinês. O próprio sufixo 'ismo’ é impensável na forma como as palavras surgem em sinogramas. Existe a designação comum Rú 儒, associada em suas origens ao estudo da tradição para assegurar o governo/gestão das obras agrícolas e hidráulicas e que, muitas vezes, denota uma ética correta do funcionário do Estado. A dependência em tratar o assunto por meio de traduções conceituais, só pode ser compensada buscando entender a experiência chinesa e não as etimologias ocidentais.

Uma distinção deve ser feita: neoconfucianismo é o movimento de ressignificação da tradição chinesa ocorrido nas dinastias Tang (618-907) e Song (960-1279). Para a atual caracterização das linhagens filosóficas associadas à persona de Confúcio utiliza-se da expressão 'novo confucianismo', situado principalmente a partir dos anos 1950, que apresenta forte caráter dialético com a filosofia ocidental e os processos de desenvolvimento-globalização. Para alguns autores é possível falar desse novo confucianismo desde os embates reformistas no fim da dinastia Qing (1644-1911). Também é comum utilizar a expressão em inglês 'confuncian revival', associada a um movimento de 
reavivamento de valores confucianos na China após a morte de Mao Zedong, em 1976. Ele inclui grande diversidade de formas de ativismo, expressões religiosas, práticas pedagógicas alternativas e mesmo a ação do Estado.

A escolha do conteúdo aqui analisado tenta atender às duas formas de análise observadas por Richard Worsman, nos trabalhos de Jiawen Ai e Sébastien Billioud. Jiawen Ai categoriza os envolvidos no novo confucianismo em posições ideológicas: marxistas, liberais e confucianos, principalmente com as permutações entre essas categorias, enquanto Sébastien Billioud analisa a ação estatal e não-estatal, bem como as ligações entre as duas para o incentivo das práticas pró-Confúcio. Essa categorização metodológica ganhou destaque ao ser formada em trabalho antropológico de campo com as pessoas, templos e escolas envolvidas no atual reavivamento de Confúcio. Como existem esforços de categorizar esses processos históricos no debate globalização-ocidentalização, adota-se aqui uma postura levemente inspirada na proposta de identificar uma geografia do saber/conhecimento presente nos trabalhos dos autores decoloniais como Anibal Quijano e Walter Mignolo. Assim tenta-se destacar aspectos não muito observados nos autores, principalmente em língua inglesa.

\section{Uma retrospectiva das críticas contra Confúcio}

Apesar de ter sido a base do pensamento administrativo, educacional e da cultura política chinesa por séculos, a tradição do confucianismo passou por sérias críticas ao longo da história. A maior parte destas representou ressignificações da própria ortodoxia confuciana chinesa, ou disputas intelectuais com taoístas e outras tendências do pensamento na China. Contudo, no século XIX, um número considerável de acontecimentos e processos forçaram revisionismos e críticas, outrora praticamente impensáveis, ao personagem Confúcio. Com as Guerras do Ópio (1839-1860) e as ações imperialistas dos europeus, e posteriormente do vizinho japonês, penetraram na China valores associados à necessidade de mudança e modernização que alguns chamariam até de ocidentalização. Mas os reformadores da geração de Kang Youwei (1858-1927) ainda permaneciam ou convictos do ideal de superioridade dos valores e concepções chinesas frente os estrangeiros, ou fazendo leituras dos modelos importados a partir das próprias concepções chinesas. Num nível 
amplo, as bases ideológicas da sociedade chinesa permaneceram as mesmas até o século $\mathrm{XX}$.

\subsection{Combatendo a Mentalidade Antiga}

Em 1905, ocorreu a abolição do sistema de exames públicos, elemento básico na legitimação da importância do confucianismo para o funcionamento do Estado Imperial. Entre os últimos anos do século XIX e o Movimento do Quadro de Maio de 1919 viveu, nas palavras de Anne Cheng, uma geração que corresponde " $a$ última a conhecer a educação à antiga, mas também a primeira a enfrentar o choque das ideias vindas do Ocidente moderno". ${ }^{4}$ A Dinastia Qing realizou esforços tardios de modernização do país, que visavam manter a monarquia e unidade nacional de forma semelhante ao que o Japão Meiji fizera. Estudantes foram enviados ao exterior, principalmente ao Japão, para contribuir com a restauração do poder imperial. Contudo, acabaram por acelerar a derrubada do mesmo. Chen Duxiu (1879-1942), co-fundador do Partido Comunista e editor do periódico a Nova Juventude, com grande influência dentro do Movimento do Quatro de Maio, deu um testemunho pessoal da mudança de pensamento que teve ao aceitar 'aprender com o ocidente':

Em nossa juventude, estávamos ocupados em estudar a composição em oito partes e a discutir sobre o saber antigo. Muitas vezes, não tínhamos senão desprezo pelos letrados que aprendiam as línguas europeias e discutiam sobre o novo saber: todos eram escravos dos ocidentais, indignos de nossa tradição. Foi somente ao ler os escritos do Sr. Kang [Youwei] e de seu discípulo Liang Qichao que começamos a adquirir consciência de que os princípios políticos, a religião e o saber dos estrangeiros podiam trazer-nos uma grande contribuição e abrir-nos os olhos, ao ponto de fazer-nos rejeitar o passado para abraçar o presente. ${ }^{5}$

Contudo, após muito sacrifício para o discurso reformista ganhar adeptos, a República, proclamada em 1912, revelou-se uma decepção. Como apontado por John King Fairbank, ela começaria sua história com “certos atributos do liberalismo - uma imprensa livre; assembleias eleitas representando a elite local em muitos municípios, prefeituras e províncias; e um parlamento nacional organizado, sobretudo, pelo recém-criado Partido

\footnotetext{
${ }^{4}$ CHENG, Anne. História do pensamento chinês. Tradução de Gentil Avelino Titton. Petrópolis: Vozes, 2008, p. 728.

5 “Bo Kang Youwei zhi zongtong zongli shu” ("Discussão crítica da carta de Kang Youwei ao presidente e ao Primeiro Ministro"), in Xin qingnian (A Nova Juventude), 1916. CHENG, Anne. História do pensamento chinês. Op. cit., p. 729.
} 
Nacionalista". ${ }^{6}$ Mas, por outro lado, o primeiro presidente, Yuan Shikai (1859-1916), era um militar e agiu conforme a clássica história imperial chinesa tentando instaurar sua própria dinastia.

O Movimento Quatro de Maio de 1919 se desencadeou contra a decisão, em Versalhes, de deixar concessões alemãs na província chinesa de Shandong para o controle dos vizinhos japoneses. A elite intelectual chinesa então passou a apresentar um maior espírito de protesto, incluindo o de renovação cultural da China. A educação clássica confuciana foi criticada por essa nova elite intelectual cuja infância fora marcada por ela, mas que, na vida adulta, estudou no estrangeiro e voltou para lutar pela modernização do próprio país. O confucianismo foi questionado como representante de uma China Arcaica, em oposição clara à Nova China que era desejada.

Os intelectuais do Quatro de Maio separaram-se em dois grupos - os acadêmicos de Hu Shi e Fu Sinian, concentrados como estudiosos na recuperação e revalidação da história e cultura da China, e ativistas políticos como Chen Duxiu e Zhang Guotao, que se juntaram para formar o movimento comunista chinês. ${ }^{7}$

A mudança para a opção revolucionária se impus frente à fragmentação políticomilitar da nação, no período denominado Era dos Senhores de Guerra (1916-1928), após o governo de Yuan Shikai, seguido do contexto complexo em que ocorreram a Expedição do Norte de 1928, para reunificação do país, as duas Guerras Civis da China (1927-1937 e 1946-1949), a Guerra das Planícies Centrais (1930) e a 2a Guerra Sino-Japonesa (19371945). O caráter extraordinário e a força de acontecimentos de grande calamidade enfrentados pela população chinesa permitem explicar como foi aceite, de forma radical, uma ideologia e estrutura de pensamento estrangeira, o marxismo revolucionário. Caracterizando todos esses processos, pode-se afirmar que "Desde o fim do século XIX, a China não pode mais considerar-se como formando um mundo à parte, nem evitar a referência ocidental." ${ }^{8}$ Estes marcos atestam mudanças de impacto em todas as esferas da sociedade chinesa, cuja organização dominante era a família confuciana da qual o Estado deveria ser um espelho.

\footnotetext{
${ }^{6}$ FAIRBANK, John King. GOLDMAN, Merle. China: uma nova história. Tradução de Marisa Motta. $3^{a}$ Ed; Porto Alegre: L\&PM, 2008, p. 237.

${ }^{7}$ Ibidem.

${ }^{8}$ CHENG, Anne. História do pensamento chinês. Op. cit., p. 731.
} 


\subsection{A Grande Revolução Cultural Proletária}

Com a proclamação da República Popular da China, os chineses passaram a ter que adotar maior cuidado ao realizarem qualquer elogio ao pensamento confuciano, ou mesmo à tradição imperial chinesa. O Partido Comunista da China prezou então pela manutenção de uma auto-imagem de salvador da China do passado imperial 'feudal', tornando difícil qualquer valorização da tradição do confucianismo, do budismo ou taoísmo. No entanto, aspectos da tradição confuciana persistiam, e seus simpatizantes estavam em todos os níveis da sociedade.

Jonathan Spence aponta que apesar de oficialmente o PCC ser contrário a Confúcio, nos decênios de 1940 e 1950, Liú Shăoqí (1898-1969), presidente da China entre 19591968, no livro Como ser um bom comunista [1939], acabou "misturando tradições confucianas de moralidade e disciplina com uma linha marxista-leninista clássica e apresentando o conjunto em fervorosa linguagem revolucionária". ${ }^{9} \mathrm{Ou}$ seja, chineses aprendiam o que era comunismo, fidelidade ao partido e como ser um revolucionário a partir de uma estrutura de narrativa tradicional do ensino moral confuciano.

Tais nuances num nível tão alto do partido evidenciam também que, mesmo com a proclamação da República Popular, os defensores/simpatizantes de Confúcio teriam que ser tolerados pelo simples fato de constituírem parte significativa da elite escolarizada do país, sem a qual o processo de modernização econômica seria impossível, e o sonho comunista jamais alcançado. Após a fuga de intelectuais, em 1949, ocorreu um enfraquecimento significativo do confucianismo que, a partir dos anos 1950, teve em Taiwan o principal polo de preservação de seu pensamento e conjunto de práticas rituais ${ }^{10}$. Mou Zongsan (1909-1995), o primeiro grande defensor do neoconfucianismo filosófico contemporâneo, por exemplo, se exilou em Taiwan já em 1949.

Com a dificuldade de garantir a fidelidade dos intelectuais chineses perante o partido e, ao mesmo tempo, como estratégia para atender a demanda por maior liberdade,

\footnotetext{
${ }^{9}$ SPENCE, Jonathan D. Em Busca da China Moderna: Quatro séculos de história. Tradução de Tomás Rosa Bueno e Pedro Maria Soares. São Paulo: Companhia das Letras, 1995, p. 494.

${ }^{10} \mathrm{O}$ Ritual, no confucianismo, pode ser compreendido tanto em práticas de celebração ao ciclo da vida, como casamentos, funerais, culto aos antepassados, como numa concepção mais antiga de práticas civilizacionais necessárias para manter a cultura humana. O bom governante então deveria zelar pela manutenção de rituais cívicos incentivados pelo Estado.
} 
entre 1956-1957, foi lançada a Campanha das Cem Flores, cujo efeito catastrófico é descrito da seguinte forma por J. King Fairbank:

Mao fez uma estimativa de que de um total de no máximo cinco milhões de intelectuais [...] não mais de $3 \%$ eram hostis ao marxismo. [...]

Os intelectuais chineses sabiam que o fato de se exporem poderia custarlhes a vida. Por isso, permaneceram calados durante um ano. Mas em maio de 1957 começaram a criticar o regime do PCC com veemênciaseus princípios básicos, estilo de trabalho, doutrinas e práticas passaram a sofrer ataques. Em cinco semanas, a Campanha das Cem Flores foi dissolvida. ${ }^{11}$

$\mathrm{O}$ clima de intolerância às críticas feitas ao partido se instalou desencadeando a campanha antidireitista de 1957-1958 e a Campanha Socialista de Educação de 1963. É verdade que esse histórico prévio à Revolução Cultural pode ser entendido associado às experiências do próprio PCC durante o processo de guerra civil, como apontando por Jonathan Spence: "O PCC aprendera, durante a Campanha de Retificação de 1942, a se auto-investigar, forçar seus membros à autocrítica e utilizar a pressão de grupo e a intimidação para chegar a um aparente consenso." ${ }^{12}$ Mas também se pode associar todas essas campanhas, que se auto-proclamavam como de caráter 'retificador', com a concepção política tradicional chinesa de retificar para governar, presente na cultura política imperial. Assim como o primeiro imperador necessitou 'retificar os nomes', unificando a escrita e fazendo com que o que fosse escrito correspondesse com o que fosse parte do real, a Revolução Cultural caminhou para um processo de 'retificar os caracteres' e purificar as concepções de classe das massas compostas por uma juventude que não tinha vivido nem a opressão imperialista estrangeira, nem a opressão interna das classes dominantes.

A intolerância máxima ao confucianismo aconteceu com o aniversário de Confúcio em novembro de 1966, quando ocorreu a invasão, destruição e pilhagem dos chamados '3 sítios de Confúcio’: Kǒng miào (Templo de Confúcio), Kǒng lín (Cemitério de Confúcio) e Kŏng fŭ (Casarão da Família de Confúcio), localizados na cidade de Qufu, província de Shandong. Esse ato de destruição da memória material foi divulgado pela impressa popular do país como um grande sucesso no combate ao revisionismo anti-revolucionário. A partir de 1966, desencadeu-se, na China continental, o fenômeno complexo da Grande Revolução Cultural Proletária (1966-1976), ocorrendo a maior mobilização em número de pessoas e

\footnotetext{
${ }^{11}$ FAIRBANK, John King. GOLDMAN, Merle. China. Op. cit., p. 336-337.

${ }^{12}$ SPENCE, Jonathan D. Em Busca da China Moderna. Op. cit., p. 506.
} 
esforços para praticar atos de crítica ao confucianismo: por um lado, uma série de disputas políticas entre os diversos quadros do PCC; por outro, um processo de real esforço para abolir as opressões herdadas da sociedade de classes anteriormente existente.

De fato, para a maior parte da população, a educação ainda era de difícil acesso, e constituindo o ponto chave da perpetuação dos privilégios de antigas classes dominantes, herdeiras da educação confuciana. O símbolo maior do conservadorismo antigo, apegado à tradição e empecilho para o sucesso revolucionário, era facilmente visto pelo PCC como o próprio Confúcio. Num material didático e de propaganda política de 1974 - aspectos então indissociáveis - o personagem foi descrito como criminoso, escravista e fracassado. Usado por jovens e adultos, o discurso contido no material diz claramente: "Todos os reacionários louvam os confucianos." E sobre Lin Biao (1907-1971), que inicialmente estivera à frente da Revolução Cultural junto a Mao Zedong, é dito:

Não era diferente de quaisquer outros reacionários da história que estavam à beira de serem destruídos, ele elogiou Confúcio e se opôs à lei, usando Confúcio e Mêncio em sua tentativa de usurpar o poder e em seu arsenal ideológico reacionário inclinado a restaurar o capitalismo. ${ }^{13}$

O peso das campanhas Contra Confúcio e Lin Biao, "pī Lín pī Kǒng yùn dòng”, foi tamanho, que sinólogos muito renomados não apontaram quase nenhuma expectativa de que o confucianismo viesse a ser tolerado novamente pelo PCC. Anne Cheng, por exemplo, em 1997, insiste em reforçar o impacto da adesão chinesa ao marxismo:

mesmo que se tenha insistido em sua chinização no pensamento de Mao Tse-Tung, não deixa de ser verdade que se trata de uma atitude de fazer tabula rasa. Entre 1966 e 1976, a Revolução Cultural foi disto uma expressão que deixou marcas profundas na sociedade chinesa. ${ }^{14}$

Mas, em alguns trabalhos como Images for Iconoclasts: Images of Confucius in the Cultural Revolution ${ }^{15}$, Deborah A. Sommer sublinha que, ao fazer leituras críticas coletivas ao confucianismo e com a multiplicação de representações negativas de Confúcio em ilustrações, foi popularizado principalmente para as novas gerações pós 1949, o acesso a frases e conceitos que estavam cada vez mais restritos a uma minoria da população desde a segunda metade do século XIX.

${ }^{13}$ GAN, Xiao. Kǒng Lăo èr Zuì'è de yīshēng. Ilustrações de Gu Bingxin e He Youzi. Shanghai: Shanghai Renmin, 1974, p.23.

${ }^{14}$ CHENG, Anne. História do pensamento chinês. Op. cit., p. 730.

15 SOMMER, Deborah A. "Images for Iconoclasts: Images of Confucius in the Cultural Revolution”. In: East-West Connections: Review of Asian Studies. Vol. 7.1, 2007, p. 1-23. 
Outro aspecto fundamental é a posição do PCC frente às outras escolas tradicionais chinesas, as jiā 家. Apesar de oficialmente se opor ao confucianismo, outra escola tradicional muito próxima do mesmo, considerada, por alguns, como aspectos de uma mesma tradição, o legismo, Fă jiā 法家, foi assumida como posição política oficial do governo. Se considerada essa condição, o embate entre tradição chinesa e importação de modelos ocidentais pende em favor da primeira. E é essa a abordagem adotada por Tong Zhang e Barry Schwartz, ${ }^{16}$ ainda na década de 1990, antes do sucesso atual do reavivamento de Confúcio. Se Confúcio foi criticado, Mozi (470-391 a. E. C.), pensador clássico e discípulo indireto do mesmo, foi exaltado por criticar seus ensinamentos. Foi elevado à categoria de intelectual proletário, por supostamente não ter ligação nobre, ao contrário de Confúcio. O PCC ignorou, talvez conscientemente, o fato que a maioria dos letrados da época dos Reinos Combatentes não pertenciam à nobreza. De qualquer modo, a eleição de Mozi como representante de um ‘proletário’ foi constituída de forma arbitrária. Mas essa concepção não era dominante, e o próprio Mao Zedong parece ter criticado os que opunham Mozi a Confúcio, colocando os dois num mesmo grupo. ${ }^{17}$

\section{A lenta retomada do personagem principal}

Os estudos pontuais em português sobre o fenômeno atual do reavivamento de Confúcio dão a impressão que, após a morte de Mao Zedong em 1976, ocorreu uma revalorização estatal do personagem de Confúcio associada ao sucesso econômico dos dois slogans: ‘um país dois sistemas’ Yīguóliăngzhì 一国两制 e, ‘Socialismo de Mercado’, Shìchăng shèhuì zhǔyì 市场社会主义. No artigo "Desenvolvimento da República Popular da China: O Novo Confucionismo e as Mudanças na Educação à Partir das Reformas Implementadas por Deng XiaoPing”, Tatiana S. Viggiani oferece uma interpretação clara do quadro atual: "O PCC tem difundido sua política desenvolvimentista junto com ideias do Novo Confucianismo visando alterar a sociedade, fornecendo mais educação ao mesmo

\footnotetext{
${ }^{16}$ ZHANG, Tong, SCHWARTZ, Barry. "Confucius and the Cultural Revolution: A Study in Collective Memory". In: International Journal of Politics, Culture and Society. Vol. 11, n 2, 1997, p. 189-212.

${ }^{17}$ BOER, Roland. Confucius and Chairmain Mao: Towards a Study of Religion in Chinese Marxism. In: Crisis and Critique. 2015 p.36-55. Disponível em: 〈http://crisiscritique.org/uploads-new/BOER.pdf>. Acessado em 10, Dezembro de 2017.
} 
tempo que tenta controlar movimentos sociais. " ${ }^{18} \mathrm{O}$ momento de mudança entre a crítica e a defesa de Confúcio é apontado: "A volta do Confucianismo como filosofia na China aconteceu principalmente, após o falecimento de Mao, em decorrência da perda de sustentação ideológica do socialismo". ${ }^{19}$ A tese da perda ideológica é comum a vários autores não pertencentes à sinologia, como por exemplo, o próprio Franscis Fukuyama em O Fim da História e o Último Homem. ${ }^{20}$ Viggiani, entretanto, não segue a interpretação do governo chinês como um Estado autoritário, e aponta um ponto de consenso para um grande grupo de pesquisadores de cunho econômico que se deparam com o rápido crescimento financeiro/industrial de países como Coreia do Sul e Cingapura. ${ }^{21} \mathrm{O}$ segundo fator de adoção do confucianismo é um reconhecimento de que "o modelo asiático de produção utilizado pelos países vizinhos, onde o desenvolvimento não significa necessariamente uma ocidentalização e suas bases eram exatamente a história chinesa e os preceitos adotados por Confúcio". ${ }^{22}$

Já o sinólogo brasileiro André Bueno aponta um novo confucianismo dentro do quadro de mudanças econômicas e sociais da China dos últimos decênios, mas apresenta um maior enfoque nos aspectos de longa duração da tradição chinesa e, considera que: “ $O$ que a China fez, pois, foi construir um marxismo próprio, re-interpretado por suas

\footnotetext{
${ }^{18}$ VIGGIANI, Tatiana S.. "Desenvolvimento da República Popular da China: O Novo Confucionismo e as mudanças na educação à partir das reformas implementadas por Deng Xiaoping”.. In: XIII Semana de Relações Internacionais da Unesp: Cultura e Direitos Humanos nas Relações Internacionais, 2015, Marília. Anais da XIII Semana de Relações Internacionais da Unesp, 2015, V. 1, p. 7.

${ }^{19}$ Idem, p. 5.

${ }^{20}$ Fukuyama, devido a seus próprios objetivos, não consegue enxergar na China um confucianismo além de uma religião tradicional sem importância. Após a Morte de Mao Zedong, ele acredita que a existência de um setor privado já denota indiscutivelmente uma liberalização política. Como visto em "Depois dos acontecimentos de 1989 a China passou a ser apenas mais um país autoritário na Ásia. Para um extenso setor da sua elite, falta ao governo legitimidade interna, especialmente para os jovens que algum dia herdarão o país e que não são guiados por uma ideologia coerente", ele coloca o vácuo ideológico para um período mais recente, numa busca dos chineses por maior liberdade individual. Essa concepção é comum a diversos autores que observam o fenômeno do confucianismo contemporâneo. O curioso é que a preocupação com o enquadramento da experiência chinesa nos conceitos ocidentais, que o mesmo não distingue de 'universais', em nenhum momento lhe permite olhar os próprios rearranjos da China com sua tradição, ou se perguntar sobre a possibilidade do confucianismo fornecer uma nova base político ideológica para legitimidade do PCC. FUKUYAMA, Francis. O fim da história e o último homem. Tradução de Aulyde Soares Rodrigues. Rio de Janeiro: Rocco, 1992, p. 64.

${ }^{21}$ Sobre os estudos neoweberianos e o novo confucianismo ver: SILVA, Rodrigo Luiz Medeiro da. "Capitalismo, confucionismo e teoria weberiana: reflexões empíricas sobre o caso sul-coreano". Tempo Social: revista de sociologia da USP. São Paulo: Scielo. Vol. 28. N1, pp.179-202. 2015. Disponível em: <https://www.researchgate.net/publication/299356242_Capitalismo_Confucionismo_e_Teoria_Weberiana_R eflexoes_empiricas_sobre_o_caso_sul-coreano>. Acessado em: 01 de Dezembro de 2017.

${ }^{22}$ VIGGIANI, Tatiana S.. "Desenvolvimento da República Popular da China.” Op. cit.., pp. 5-6.
} 
orientações filosóficas seculares, cujos conflitos internos se deram em função de radicalizações dentro do partido comunista chinês e da sociedade." ${ }^{23}$ Ao apontar a originalidade do modelo chinês, ele alerta também para

suas próprias necessidades de mudanças, que se configuram na implementação desse 'Novo Confucionismo'. [...] O Estado pretende transferir ao chinês uma partilha de responsabilidades sociais sobre a educação, as questões ecológicas, a auto-regulação do mercado, a negociação de direitos trabalhistas, etc. ${ }^{24}$

Além das análises de conjuntura, André Bueno também aponta que "o novo confucianismo' da RPC segue a linha proposta por Jiang Qing, cujas propostas tentam conciliar a questão do marxismo chinês com a reconstrução do confucionismo." ${ }^{25} \mathrm{~A}$ proposição da influência de Jiang Qing será melhor tratada a seguir. O que interessa é que a relação de partilha das responsabilidades sociais com o chinês comum se encaixa perfeitamente com o discurso humanitário do confucianismo.

\subsection{Estudos Nacionais e a "Ocidentalização"}

Wang Xiufang ${ }^{26}$ aponta a divisão clássica da história da educação na China contemporânea: o período Mao Zedong (1949-1976); o período das reformas na liderança de Deng Xiaoping (1977-1997); e as reformas a partir do governo de Jiang Zemin (1997 até o presente). No que tange a aceitação do confucianismo na China, poderia se acrescentar ainda uma nova etapa a partir de 2008, quando os Jogos Olímpicos e a maior visibilidade mundial das relações do governo com o confucianismo ficaram perceptíveis para o mundo.

O período das reformas pós Mao Zedong não foi marcado imediatamente por um grande incentivo e revalorização do confucianismo. Como dito anteriormente, Taiwan constituiu num refúgio para os filósofos que propuseram um novo confucianismo. Mou Zongsan, retornou para Hong Kong, e o fenômeno acadêmico foi mais internacional e menos chinês. Proponho aqui a articulação internacional entre diferentes atores: existem diversos movimentos nacionais que rearticularam a herança confuciana frente ao processo de globalização no século XX, como no caso da Coreia do Sul e da Malásia. Existe também outro processo dentro do que é chamado Grande China, ou China Cultural, que engloba

\footnotetext{
${ }^{23}$ BUENO, André. Compreendendo o "Novo Confucionismo": a possível transição do marxismo para o confucionismo na China Contemporânea. Revista Mundo Antigo. Ano I, Vol. I, Junho de 2012, p. 135.

${ }^{24}$ Ibidem.

${ }^{25}$ Idem, p. 133.

${ }^{26}$ WANG, Xiufang. Education in China since 1976. Jefferson: Library of Congress, 2003.
} 
territórios de colonização chinesa, como Cingapura e Taiwan e, as zonas autônomas da China que foram colonizadas por europeus, como Hong Kong e Macau. Por último, um movimento mais acadêmico em nível mundial, pode ser exemplificado na figura de Tu Weiming, discípulo de Mou Zongsan (1909-1995), que nasceu na China em 1940, mas fez sua carreira nos Estados Unidos nos anos 1960, e voltou ao seu país recentemente como professor visitante de diversas universidades. Esses movimentos partem de fora da China para dentro da mesma, como Wang Caigui, ativista confuciano de Taiwan, que foi, desde os anos 1990 se articulando para conseguir espaços na RPC, e ao longo dos anos 2000 angariou cada vez mais simpatizantes, pessoas que, no continente, reconheceram e passaram a lutar por espaços para revalorização da tradição confuciana.

Uma possível origem interna do reavivamento de Confúcio está associada ao desenvolvimento da chamada 'herança crítica' e ao espaço para discussões a partir dos ‘estudos nacionais' Guóxué 国学. No período de Deng Xiaoping, o redirecionamento administrativo e educacional do Estado buscou uma atualização para atender níveis de competitividade frente a outros sistemas educativos no mundo. Mas, ao mesmo tempo, o PCC necessitava de uma herança nacional 'crítica'. Conforme Tong Zhang e Barry Schwartz: "O objetivo final do governo de Deng Xiaoping não foi movimentar a China para seu estágio pré-Revolução Cultural, mas sim para um novo lugar no mundo." ${ }^{27} \mathrm{E}$ nesse contexto que intelectuais chineses, interessados e desvinculados da academia, filiados e não filiados do PCC e, o próprio Ministério da Educação, passaram a se envolver mais com o que ficou conhecido como 'estudos nacionais'. Na prática, não se valorizava ou estudava Confúcio para se superar o Maoísmo, mas se estudava a tradição chinesa como forma de estimular nacionalmente um clima em que a China fosse vista como capaz de fazer grandes coisas, sua tradição apenas comprovando tal fato.

O exemplo de Fang Keli pode ilustrar a tolerância/incentivo ao estudo dos sistemas de pensamento nativos, nos anos 1980. Nascido em 1938, ele se filiou ao PCC em $1962 .^{28}$ Receberá grande reconhecimento oficial nos anos 1980, incluindo dois prêmios governamentais importantes como o "Trabalho Modelo" em Tiajin 1984 e, em 1988,

\footnotetext{
${ }^{27}$ ZHANG, Tong; SCHWARTZ, Barry. "Confucius and the Cultural Revolution: A Study in Collective Memory". International Journal of Politics, Culture and Society. Vol 11, n. 2, 1997, p. 202.

${ }^{28}$ China Who's Who Society. Disponível em: <http://www.chinesewhoswho.org/enmrdata/index.php?docview-3077>. Acessado em 15 de Dezembro de 2017.
} 
"Jovens e Pessoas de Meia Idade com Contribuição Extraordinária". O incentivo governamental às suas produções acadêmicas gerou projetos de pesquisa sobre o confucianismo entre 1986-1995, resultando em mais de 400 trabalhos publicados. ${ }^{29}$ Sua grande contribuição, enquanto pesquisador da história da filosofia chinesa, foi fornecer arcabouço teórico para o governo de que existe compatibilidade entre o confucianismo e a modernidade. Assumindo uma postura diferenciada dos neoconfucianos Tu Weiming e Mou Zongsan, para os quais, além de uma rica tradição cultural, o confucianismo teria seu melhor aspecto numa dimensão religiosa, Fang Keli conseguiu se consagrar partindo primeiro dos estudos nacionais para que, depois de ser reconhecido dentro da hierarquia partidária e acadêmica, tivesse legitimidade ao falar de Confúcio. Essa legitimidade lhe rende, desde 2001, a participação no Conselho de Estado da RPC. Se categorizado pela proposta de Jiawen Ai, ele seria um marxista confuciano, enquanto que no critério de análise de Sébastien Billoud, ele representaria um incentivo estatal, ao contrário de Mou Zongsan e Tu Weiming, os quais tiveram carreiras independentes do PCC. Apesar de comporem lugares diferentes dentro da China Cultural, usando uma expressão de Tu Weiming, ${ }^{30}$ e da falta do aspecto religioso para Fang Keli, todos contribuíram na formulação teórica, bem como na legitimação dos discursos pró-Confúcio frente às ideias ocidentais. Esse processo de afirmação da capacidade do confucianismo é importante, devido à concepção ocidental e chinesa, principalmente dos críticos, de que o pensamento confuciano seria, por sua essência, contrário aos processos de modernidade/modernização.

A virada dos anos 1980 para 1990 constituiu-se de mudanças muito mais significativas em relação ao confucianismo do que a mudança de Mao para Deng. Um exemplo curioso, que mostra aspectos da própria cultura política chinesa, ocorreu na comemoração do $2540^{\circ}$ e do $2545^{\circ}$ aniversários de Confúcio em 1989 e 1994, quando Jiang Zemin fez aparições não anunciadas nos eventos, denotando uma aprovação oficial do governo, principalmente na segunda visita, quando ele já era o presidente da RPC. ${ }^{31}$

\footnotetext{
${ }^{29}$ WORSMAN, Richard. Tradition, Modernity ad the Confucian Revival: An Introduction and Literature Review of New Confucian Activism. History Honors Papers. 14, 2012, p. 53.

${ }^{30}$ Para o conceito de China Cultural ver: TU, Wei-ming. "Cultural China: The Periphery as the Center". In: Daedalus. Research Library, N. 120, 1991; 120, pp. 1-32.

31 AI, Jiawen. "The Refunctioning of Confucianism: The Mainland Chinise Intellectual Response to Confucianism since the 1980s. In: Issues \& Studies. Vol. 44. N², 2008, p. 32. ZHANG, Tong, SCHWARTZ,
} 
Além da postura mais estratégica adotada por intelectuais como Fang Keli, outros personagens elaboraram suas visões mais peculiares de como o confucianismo pode contribuir com a China. Apontado como um dos mais influentes neoconfucianos da RPC, nascido em 1953, Jiang Qing, na opinião de Daniel Bell, "escreveu a defesa mais sistemática e detalhada de crenças políticas [confucianismo] desde o estabelecimento da República Popular da China." ${ }^{32}$ Sua obra e propostas apontam para o uso de textos clássicos do confucianismo, atentando principalmente para Xunzi (310-235 a.E.C.) e Dong Zhongshu (195-104 a.E.C.). Jiang Qing oficialmente se filia à tradição textual do Gongyang $^{33}$, que basicamente é uma versão dos Anais da Primavera e Outonos seguida, em cada parte, por comentários atribuídos a Confúcio. Richard Worsman destaca o fato de que, durante o governo do Imperador Wu, no século II a.E.C., a obra de Dong Zhongshu “foi instrumentalizada no estabelecimento de uma Universidade Imperial no auge de uma burocracia civil confuciana. ${ }^{{ }^{34}} \mathrm{O}$ que fundaria o pensamento político de Jiang Qing seria justamente as crenças comum ao confucianismo de como o imperador deveria governar o Estado.

A concepção de sábio-rei é marcadamente clássica na história do confucianismo, existindo entre muitos dos membros da burocracia estatal. Derivando dela uma proposta de nova organização política para a China, Jiang Qing tenta atender os debates metafísicos e civis existentes na tradição chinesa em torno do Mandato do Céu Tiānmìng 天命. Propõe um modelo de legislativo em três câmaras, atendendo ao ideal de unir o Céu, a Terra, e a Humanidade. O modelo tricameral corresponderia a três 'casas': a Casa dos Confucianos Aprofundados, a Casa da Continuidade Nacional e, a Casa dos Plebeus ou do Povo. Essa estrutura de governo difere completamente de uma proposição no enquadramento ocidental de divisão dos três poderes e demonstra um esforço de atualização da tradição confuciana para as exigências da China contemporânea. Worsman, citando Ruichang Wang, aponta que a Casa dos Confucianos Aprofundados seria eleita de forma 'independente', 'nãogovernamental' e por um grupo de 'estudiosos confucianos' ${ }^{35}$ Surge então um debate sobre

Barry. "Confucius and the Cultural Revolution: A Study in Collective Memory". In: International Journal of Politics, Culture and Society. Vol. 11, n 2, 1997, p. 203.

${ }^{32}$ WORSMAN, Richard. Tradition, Modernity and the Confucian Revival. Op. cit., p. 62-63.

${ }^{33}$ Idem, p. 66.

${ }^{34}$ Ibidem.

${ }^{35}$ Idem, p. 69. 
a autonomia desse grupo frente ao PCC, e para Ruichang Wang essa autonomia não significaria necessariamente a deslegitimação do Estado. Tal interpretação pode ser apoiada dentro de qualquer análise que considere que a função da categoria dos confucianos dentro da China Imperial, seria a base da legitimação das lideranças políticas.

Com a proposta não-democrática de Jiang Qing, constitui-se uma outra variação do novo confucianismo em relação às propostas de Tu Weiming e, da parte do grupo que Jiawen Ai chamaria de liberais confucianos, para os quais as liberdades individuais, marcos de uma tradição ocidental poderiam ser adquiridas dentro de um próprio referencial chinês. A proposta de Jiang Qing difere também da tradição de Mou Zongsan, e tece críticas a vários outros confucianos do século $\mathrm{XX}$, revelando variações consideráveis entre os que se portam como defensores de Confúcio na China, e atenta para a diversidade e não consenso entre as proposições.

Um intelectual igualmente original é Kang Xiaoguang ${ }^{36}$ (1963), professor da Universidade do Povo, em Beijing. Sua obra se filia à outra linhagem dentro da tradição confuciana, não ao discípulo de Confúcio Xunzi, mas à Mêncio, Mengzi (372-289 a.E.C.), tido como a segunda vertente principal do confucianismo. Os debates em educação e no como governar caminharam entre os confucianos clássicos para questões morais complexas sobre a natureza humana. Nesse processo, dimensões mais ritualísticas, também interpretadas como religiosas, desenvolveram-se. A proposição de uma religião estatal-civil pode ser remontada ao próprio Kang Youwei no século XIX. Curiosamente, em 2015,

\footnotetext{
${ }^{36}$ David Ownby aponta características importantes de sua trajetória, comum a um grande número dos defensores do confucianismo que é a formação voltada ao ramo das ciências e tecnologia. "While his early schooling may have been disrupted by the Cultural Revolution, he would not have been a Red Guard, a sent-down youth, or a worker-peasant-soldier university student. He entered the National University of Defense Technology in the Department of Systems Engineering and Mathematics in 1981, as the last of the worker-peasant-soldier cohort graduated from university. The following year he transferred to the Dalian University of Technology in the Department of Applied Mathematics, and earned his undergraduate degree in 1986. Between 1986 and 1990 he taught in the Agronomy Department of the Shenyang Agricultural University in his home town of Shenyang. When he mentions the events of 1989 in his writings, he refers only to the "turbulence" of the times and provides little commentary or analysis of the student demonstrations or the government suppression. In 1990 Kang began his graduate studies in the Department of Ecology at the Graduate School of the Chinese Academy of Sciences in Beijing, completing a Master's degree in 1993. His move to the capital coincided with the fashioning by Chinese authorities of a muscular response to Western criticisms of the events of 1989: emphasis on cultural nationalism and patriotism, and defence à $l$ 'outrance of Chinese institutions and practices (White Paper on Human Rights, etc.)". OWNBY, David. Kang Xiaoguang. "Social Science, Civil Society, and Confucian Religion". China Perspectives: Religious Reconfigurations in the People's Republic of China. $\mathrm{N}^{\circ}$ 4, 2009, p. 101 b.
} 
funda-se a Kŏng shèng huì 孔圣会, a Congregação Confuciana que tem Jiang Qing como seu presidente. ${ }^{37}$

David Ownby atesta que a proposta de Kang Xiaoguang de estabelecer uma religião confuciana com caráter nacional, pode parecer impraticável, mas o mesmo considera a posição de Kang como sendo extremamente pragmática por abarcar

as realidades das relações entre o Estado e a sociedade, afetadas pela religião, raramente encontradas em comentários publicados sobre a religião na China, uma avaliação em grande parte baseada em uma análise sensível das origens e implicações do caso de Falun Gong. Em essência, Kang propõe que o governo da China modifique sua posição contraditória em relação à religião criando uma própria, aproveitando o ressurgimento do entusiasmo popular por vários aspectos da prática confuciana [...] Se o projeto é utópico, certamente não é desprovido de certa lógica, embora coloque implicitamente a questão do grau em que a China se tornou uma sociedade genuinamente secular. ${ }^{38}$

Além da proposição de uma utilização estatal de um confucianismo enquanto moral religiosa, processo típico do pensamento derivado de Mêncio, Kang Xiaoguang revela-se fortemente crítico da influência ocidental na China. Sua proposta tenta conciliar a ideologia comunista do PCC, com a ortodoxia do confucianismo, ao destacar a função legitimadora da "harmonia e das regras sociais". ${ }^{39} \mathrm{Em}$ suas falas, ele opõe ao processo de 'ocidentalização' da China uma 'confucianização', ${ }^{40}$ ao mesmo tempo em que rejeita a democracia liberal ocidental, argumentando com base nos textos clássicos confucianos e utilizando um discurso que lentamente foi ganhando legitimidade frente o PCC. O conceito de Hexie Shehui, 'Sociedade Harmoniosa', por exemplo, teve grande utilização nos pronunciamentos oficiais do presidente Hu Jintao. A proposição de Kang se encaixa com a fala de $\mathrm{Hu}$ "Promover a cultura chinesa e construir a base espiritual comum da nação chinesa." 41

\footnotetext{
${ }^{37}$ As fundações de diversas congregações confucianas são melhor observadas nos trabalhos de Sébastien Billoud como o The Sage and the people. Elas foram articuladas por diversas pessoas, com diferentes concepções do que é o confucianismo, inclusive se ele constitui uma religião ou não.

${ }^{38}$ OWNBY, David. Kang Xiaoguang. "Social Science, Civil Society, and Confucian Religion”. Op. cit., p. $111 \mathrm{a}-\mathrm{b}$.

${ }^{39}$ WORSMAN, Richard. Tradition, Modernity and the Confucian Revival. Op. cit., p. 76.

40 Only Confucians can rule China, says Kang Xiaoguang. Disponível em: <http://www.franzbleeker.de/modern_society_kangxiaoguang_confucianism_001.html . Acessado em 20 de Dezembro de 2017.

${ }^{41}$ AI, Jiawen. "Two Sides of One Coin: The Party's Attitude Toward Confucianism in Contemporary China". The Journal of Contemporary China. 18, 61, 2009, p. 696.
} 
Como se tentou demonstrar aqui, é difícil argumentar em um projeto bem definido de patrocínio e expansão do confucianismo após a morte de Mao Zedong. Pode-se falar do grande cuidado do PCC ao apoiar ou não os novos confucianos e, ao mesmo tempo, da existência de grande diversidade entre os mesmos e dos problemas que eles tiveram e terão para se encaixarem e ganharem maior legitimidade frente às lideranças chinesas, não impedindo que as estruturas de pensamento, e os marcos tradicionais ganhassem mais e mais espaço.

\section{Considerações Finais}

Apesar de todos os ânimos com o movimento de reavivamento de Confúcio, o século XXI chega à China com uma diversificação grande de propostas para o país. Os confucianos pontuais aqui citados remetem mais à diversidade da utilização da tradução textual confuciana do que às pautas sociais abrangidas pelos ativistas confucianos de hoje. Um forte movimento ecológico, por exemplo, está sendo associado aos slogans de sociedade harmoniosa e ao próprio retorno de Confúcio. Os problemas ambientais e sociais advindos do crescimento econômico que sustenta o progresso social fornecido pelo PCC, são pontos chave na legitimação do governo, tanto quanto os aspectos políticos e culturais frente ao ocidente. Por outro lado, o impacto das ideias de educação confuciana no sistema educacional chinês ainda está longe de ser compreendido. Por mais inovadoras que as ideias de valorização do conhecimento clássico pareçam, o ensino básico chinês ainda não sofreu um impacto tão significativo. A existência de movimentos como a 'leitura de textos clássicos para crianças', ou as escolas alternativas à educação obrigatória formal, abarcam uma pequena quantidade de pessoas. Não se sabe ainda como o reavivamento de Confúcio pode alterar o currículo e a forma da educação de massa na China.

Se nos anos 1980 e 1990, os Estudos Nacionais podiam ser utilizados como 'cavalo de Tróia' para os defensores do pensamento de Confúcio, a grande mudança notada é que hoje ele pode ser visto como o representante legítimo de toda tradição chinesa frente aos valores ocidentais. Transcendendo os debates entre o PCC e os novos confucianos, outras tradições chinesas como o budismo participam desse processo. Sébastien Billoud nota que, no nível das pessoas comuns, são templos budistas os primeiros locais que comunidades escolheram para executar seus grupos de leituras dos textos clássicos. A fronteira entre o 
movimento acadêmico e popular é variável e parece se afastar das principais concepções existentes formadas pelo aparato conceitual da modernidade europeia.

No que tange às análises em torno de uma ocidentalização supostamente necessária para o processo de crescimento econômico, o que parece mais difícil ao aparato epistemológico ocidental é conseguir admitir a existência de outros projetos de 'modernidade', como uma 'modernidade chinesa', cuja base seria a fluidez dialética entre os conceitos antagônicos que pertencem à modernidade ocidental. Tradicional e moderno, não seriam necessariamente essências opostas que inibem a existência da outra, o mesmo se aplicando aos conceitos de ocidental e oriental. A 'modernidade chinesa', como talvez muitas outras, não seria nem tradicional nem moderna, tal abstração conceitual que faz as análises "da história imperialista e das transformações culturais é categoricamente limitada".42

Uma análise das outras tradições frente ao fenômeno do novo confucianismo ainda é inexistente. Por exemplo, não se tem esforços para entender o como as relações da China com a América Latina e o Brasil podem ser influenciadas pelas concepções defendidas pelos ativistas confucianos. Se os norte-americanos estão diretamente se envolvendo com alguns setores do novo confucianismo acadêmico, não existe no vocabulário de suas pesquisas qualquer perspectiva de relacionar o posicionamento da China frente aos outros espaços postos em segundo plano pela modernidade europeia. Se os chineses conseguiram, mais uma vez, afirmar para si mesmos e para os ocidentais que sua própria tradição é tão válida como a ciência e filosofia dos europeus e americanos, como eles irão se comportar frente aos africanos, latinos e demais povos fora da China cultural é uma questão em aberto.

\section{Referências bibliográficas}

ABUD, Katia Maria. A guardiã das tradições: a História e seu código curricular. Educar em Revista. Curitiba: Editora UFPR. N 42. pp. 163-171, 2011.

AI, Jiawen. "The Refunctioning of Confucianism: The Mainland Chinise Intellectual Response to Confucianism since the 1980s”. Issues \& Studies. Vol. 44. N², 2008. pp. $29-78$.

AI, Jiawen. "Two Sides of One Coin: The Party's Attitude Toward Confucianism in Contemporary China”. The Journal of Contemporary China. 18, 61, 2009, pp. 689-701.

BAI, Tongdong. China - The Political Philosophy of the Middle Kingdom. Zed Books, 2012.

\footnotetext{
${ }^{42}$ WORSMAN, Richard. Tradition, Modernity ad the Confucian Revival.Op. cit., p. 21.
} 
BILLIOUD, Sébastien. THORAVAL, Joel. The Sage and the people: the Confucian revival in China. New York: Oxford University Press, 2015.

BOER, ROLAND. "Confucius and Chairmain Mao: Towards a Study of Religion in Chinise Marxism". Crisis and Critique. 2015 p. 36-55. Disponível em: <http://crisiscritique.org/uploadsnew/BOER.pdf>. Acessado em 10, Dezembro de 2017.

BUENO, André. "Compreendendo o "Novo Confucionismo": a possível transição do marxismo para o confucionismo na China Contemporânea". Revista Mundo Antigo. Ano I, Vol I, Junho de 2012. pp.125-138.

CHENG, Anne. História do pensamento chinês. Tradução de Gentil Avelino Titton. Petrópolis: Vozes, 2008.

FAIRBANK, John King. GOLDMAN, Merle. China: uma nova história. Tradução de Marisa

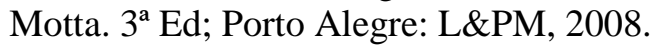

FUKUYAMA, Francis. O fim da história e o último homem. Tradução de Aulyde Soares Rodrigues. Rio de Janeiro: Rocco, 1992.

GAN, Xiao. Kǒng Lăo èr Zuì'è de yīshēng. Ilustrações de $\mathrm{Gu}$ Bingxin e $\mathrm{He}$ Youzi. Shanghai: Shanghai Renmin, 1974.

HUNNUM, Emily. C. Education in the Reform Era. Cambridge University Press, 2008.

LEVI, Nicolas. "The Impact of Confucianism in South Korea and Japan". Acta Asiatica Varsoviensia. Varsóvia: Institute of Mediterranean and Oriental Cultures. N 26, 2013, pp. 7-16.

MAKEHAM, John (org). Neo Confucianism: a Critical Examination. Nova York: Palgrave Macmillan, 2003.

MIGNOLO, Walter. "Retos Decoloniales, Hoy". In: BORSANI, María Eugenia, QUINTERO, Pablo (orgs.). Los desafios decoloniales de nuestros días: pensar colectivo. Neuquén: EDUCO Universidade Nacional Del Comahue, 2014, pp. 23-46.

OWNBY, David. Kang Xiaoguang. "Social Science, Civil Society, and Confucian Religion”. China Perspectives: Religious Reconfigurations in the People's Republic of China. $\mathrm{N}^{\circ}$ 4, 2009, pp.101-111.

QUIJANO, Anibal. "Colonialidade do poder, Eurocentrismo e América Latina”. A colonialidade do saber: eurocentrismo e ciências sociais. Perspectivas latino-americanas. Buenos Aires: CLACSO, Consejo Latinoamericano de Ciencias Sociales, 2005, pp. 116-142.

REDYSON, Deyve. "Filosofia e Religião no Pensamento de Confúcio". GNERRE, Maria Lucia Abaurre. China Antiga: aproximações religiosas. São Paulo: Fonte Editorial, 2015, pp.11-39.

SILVA, Rodrigo Luiz Medeiro da. "Capitalismo, confucionismo e teoria weberiana: reflexões empíricas sobre o caso sul-coreano". Tempo Social: revista de sociologia da USP. São Paulo: Scielo. Vol. 28, N 1, pp. 179-202. 2015. Disponível em: <https://www.researchgate.net/publication/299356242_Capitalismo_Confucionismo_e_Teoria_We beriana_Reflexoes_empiricas_sobre_o_caso_sul-coreano>. Acessado em: 01 de Dezembro de 2017.

SOMMER, Deborah A. "Images for Iconoclasts: Images of Confucius in the Cultural Revolution”. East-West Connections: Review of Asian Studies Vol. 7.1, 2007, p. 1-23.

SPENCE, Jonathan D. Em Busca da China Moderna: Quatro séculos de história. Tradução de Tomás Rosa Bueno e Pedro Maria Soares. São Paulo: Companhia das Letras, 1995.

TU, Wei-ming. "Cultural China: The Periphery as the Center". Daedalus. Research Library, N. 120, 1991; 120, pp. 1-32. 
VIGGIANI, Tatiana S. "Desenvolvimento da República Popular da China: O Novo Confucionismo e as mudanças na educação a partir das reformas implementadas por Deng Xiaoping”. In: XIII Semana de Relações Internacionais da Unesp: Cultura e Direitos Humanos nas Relações Internacionais, 2015, Marília. Anais da XIII Semana de Relações Internacionais da Unesp, 2015, v. 1.

WANG, Xiufang. Education in China since 1976. Jefferson: Library of Congress, 2003.

WORSMAN, Richard. Tradition, Modernity and the Confucian Revival: An Introduction and Literature Review of New Confucian Activism. History Honors Papers. 14, 2012.

ZHANG, Tong; SCHWARTZ, Barry. "Confucius and the Cultural Revolution: A Study in Collective Memory". International Journal of Politics, Culture and Society. Vol. 11, n . 2, 1997, p. $189-212$. 